\title{
Palliative care professionals' willingness to perform euthanasia or physician assisted suicide
}

\author{
Julia Zenz ${ }^{1 *}$, Michael Tryba ${ }^{2}$ and Michael Zenz ${ }^{1}$
}

\begin{abstract}
Background: Euthanasia and physician assisted suicide (PAS) are highly debated upon particularly in the light of medical advancement and an aging society. Little is known about the professionals' willingness to perform these practices particularly among those engaged in the field of palliative care and pain management. Thus a study was performed among those professionals.

Methods: An anonymous questionnaire was handed out to all participants of a palliative care congress and a pain symposium in 2013. The questionnaire consisted of 8 questions regarding end of life decisions. Proposed patient vignettes were used.

Results: A total of 470 eligible questionnaires were returned, 198 by physicians, 272 by nurses. The response rate was $64 \%$. The majority of professionals were reluctant to perform euthanasia or PAS: $5.3 \%$ of the respondents would be willing to perform euthanasia on a patient with a terminal illness if asked to do so. The reluctance grew in case of a patient with a non-terminal illness. The respondents were more willing to perform PAS than euthanasia. Nurses were more reluctant to take action as opposed to the physicians. The majority of the respondents would attempt to treat the patient's symptoms first before considering life-ending measures. As regards any decision making process the majority would consult with a colleague.

Conclusions: This is the first German study to ask about the willingness of professionals to take action as regards euthanasia and PAS without biased phrasing. As opposed to the general acceptance that is respectively high, the actual willingness to perform life-ending measures is low. The German debate on physician assisted suicide and its possible legalization should also incorporate clarifications regarding the responsibility who should eventually perform these acts.
\end{abstract}

Keywords: Euthanasia, Physician assisted dying, Palliative medicine, Willingness to hasten the patient's death

\section{Background}

Euthanasia and physician assisted suicide (PAS) are highly debated upon particularly in the light of medical advancement and an aging society [1]. In this paper the definition of euthanasia is: " A doctor intentionally killing a person by the administration of drugs, at that person's voluntary and competent request" [2]. " PAS is a doctor intentionally helping a person to commit suicide by providing drugs for self-administration, at that person's voluntary and competent request" [2]. So far

\footnotetext{
* Correspondence: juliazenz@mail.de

'Ruhr-University Bochum, Universitätstr. 150, D 44801 Bochum, Germany Full list of author information is available at the end of the article
}

Germany has not passed any legislation on euthanasia or PAS. However, legislative procedure is starting in autumn this year focusing on PAS. The German Society of Palliative Care, however, has taken a stand and declared their rejection of PAS $[3,4]$. At the same time the support for euthanasia among the German public is growing [5].

But even in those countries that have legalized euthanasia or PAS there is an ongoing debate about the boundaries of these practices and questions regarding the responsibilities of physicians and nurses. Data from the Netherlands have shown that it is mostly general practitioners who perform euthanasia or PAS [6]. Those 
physicians that have admitted publicly to being involved in PAS in Germany were not palliative care specialist but practiced e.g. urology or psychiatry. Nevertheless it is the palliative care specialists, who are specifically trained in end of life care.

Various surveys regarding euthanasia and PAS have been performed [7-12]. However, only very little is known about the professionals' willingness to perform these practices especially among those trained and involved in palliative care $[9,13-17]$. Thus a study among professionals involved in the field of palliative care and pain management was performed. On the one hand the recruitment took place at a palliative care conference, which means only professionals with a current link to palliative care were included. Furthermore physicians were recruited at a pain symposium. In Germany, both pain medicine and palliative medicine are special qualifications. The special qualification pain medicine however, was introduced 5 years earlier. Both fields overlap and pain specialists have proven to play an essential role in the care of terminal patients. Symptom control at the end of life in Germany is a task that is now mainly performed by specialists rather than general practitioners as reported in countries such as the Netherlands [13, 18, 19]. In 2007 the "SAPV" (specialized out-patient palliative care) was introduced in the German code of social law thus aiming at establishing a comprehensive provision of palliative care for terminal patients [20]. Care is to be provided by multidisciplinary palliative care teams [21]. This particular group of professionals is also of special interest in the debate since some have declared euthanasia and PAS as possible outcomes of palliative care [22-24]. In the year before a study was performed at the same conference $[25,26]$. However, that study focused on support of the legalization of euthanasia or PAS rather than exploring whether the respondents would actually be willing to perform the act.

\section{Methods \\ Sample}

The study is based on an anonymous questionnaire handed out to all participants of a palliative care conference and a pain symposium in 2013. Attendants were physicians and nurses. The concept of palliative care is an interdisciplinary one. Ethical decisions take place in a team approach thus acknowledging the role of the nurses in particular. Furthermore data from e.g. Belgium or the Netherlands has shown the central role of nurses in end of life practices such as assisted dying [27-30]. In $12 \%$ of the cases it was the nurse who performed the life ending act [31]. This is a remarkable figure. Furthermore they play an essential role in the decision making process since they are often approached by both patients and physicians regarding end-of-life decisions [32, 33] This is why the study also included nurses.

\section{Instrument}

The first part of the questionnaire regarded personal data asking about gender, age, occupation and special qualification in palliative care or pain medicine.

The questionnaire consisted of 8 questions on end-oflife (EOL) decisions: Concrete patient scenarios were used. They were adapted from a questionnaire by Seale [7], which was adapted from a large British study [34]. The British social attitudes survey has been used for many years and has established itself as a useful source of evidence [7]. The survey by Seale aimed at clarifying the stance of the British medical profession regarding the legalization of euthanasia or PAS. The main issue in our survey was whether the respondent is willing to perform euthanasia and physician assisted suicide (PAS) if asked to do so by their patient. Our questionnaire avoids the use of multiple hypothetical propositions, which has proven to make the results unreliable [35]. Knowledge of the definitions of euthanasia or PAS was not required. Instead the questionnaire explicitly named the actions to be taken by the physician. Thus avoiding the bias that comes with the use of words like "euthanasia"-from the Greek: "good death" or the German "Sterbehilfe"- "help to die".

The first two questions focused on a patient with a terminal illness, questions 3 and 4 focused on a patient with a non-terminal illness. Additionally the illness was described as "painful" in order to hint at clear physical suffering [7]. The last 4 questions aimed at discovering details about the decision making process: consultation with a colleague, an attempt to treat the symptoms, duration of the treatment attempts (Table 1). Possible answers were "yes", "no" and "I don't know".

\section{Data analysis}

Statistical analysis was performed using SPSS Version 22.0 (IBM Corporation, Armonk, NY, USA). The significance level was set to $\mathrm{p} \leq 0.05$. Chi Square and exact Fisher tests were used to analyze bivariate relationships. For the dichotomous feature of a terminal or non-terminal illness the non-parametric McNemar test was used.

\section{Compliance with ethics guidelines}

The study was approved by the ethics committee of the Ruhr University Bochum (Reg. no.: 4502/2012). Consent was given by the participants in completing the questionnaire.

\section{Results}

A total of 470 eligible questionnaires were returned, 198 by physicians, 272 by nurses (Table 2). The response rate was $64 \%$. 
Table 1 Questionnaire: willingness to perform euthanasia and PAS and details of the decision making process

1. A patient has an incurable, painful illness, from which they will die, for example cancer. Would you fulfill his wish and end his life using medication?

Yes No I don't know

2. If this patient asks for it, would you give him lethal medication so that he can end his own life?

Yes No I don't know

3. A patient has an incurable, painful illness, from which they will not die. Would you fulfill his wish and end his life using medication?

Yes No I don't know

4. If this patient asks for it, would you give him lethal medication so that he can end his own life?

Yes No I don't know

5. I would make this decision by myself in order to not burden others

Yes No I don't know

6. I would not make a decision without consulting my colleagues

Yes No I don't know

7. I would first attempt to treat the patient's symptoms on order to change his wish

Yes No I don't know

8. For this treatment attempt I would estimate the following amount of time

1 week 2 weeks 4 weeks

Euthanasia and PAS in case of a terminal illness

$5.3 \%$ of the respondents would be willing to perform euthanasia on a patient with a terminal illness if asked for it. $79.6 \%$ would not be willing to do so and $14.7 \%$ were undetermined.

The willingness to take action grew in case of PAS: $13 \%$ of the respondents would be willing to perform PAS in a patient with a terminal illness. $66 \%$ refused to

Table 2 Demographics of the respondents

\begin{tabular}{lll}
\hline & & $n(\%)$ \\
\hline Gender & Male & $353(75.1)$ \\
& Not specified & $104(22.1)$ \\
Age (years) & $\leq 35$ & $49(10.4)$ \\
& $36-45$ & $97(20.6)$ \\
& $46-55$ & $230(48.9)$ \\
& $56-65$ & $83(17.7)$ \\
& $>65$ & $9(1.9)$ \\
Occupation & Not specified & $2(0.4)$ \\
Special qualification in palliative care & Nurses & $272(57.9)$ \\
& Physicians & $198(42.1)$ \\
Special qualification in pain medicine & Yes & $109(55.1)$ \\
No special qualification in either palliative & $47(23.7)$ & $89(44.9)$ \\
care or pain medicine & & $60(30.3)$ \\
\hline
\end{tabular}

do so, the proportion of respondents choosing "I don't know" grew to $20.4 \%$.

\section{Euthanasia and PAS in case of a non-terminal illness}

For a patient with a non-terminal illness the percentage of respondents willing to perform euthanasia decreased to $1.1 \%$ ( $\mathrm{p} \leq 0,05)$.

The willingness to perform PAS in non-terminal illness was $3 \%$.

\section{Differences among physicians and nurses}

Concerning a terminal illness physicians were significantly more prepared to take action in both euthanasia and PAS ( $\mathrm{p} \leq 0.05)$, see Table 3: In case of a terminal illness $7.1 \%$ of the physicians were willing to perform euthanasia as opposed to $4 \%$ of the nurses. At the same time $18 \%$ of the nurses answered by "I don't know", while it was $11 \%$ of the physicians. As regards PAS $15.7 \%$ of the physicians were willing to take action vs. $11 \%$ among the nurses. Again the nurses were more often undecided in their answer: $23.9 \%$ chose "I don't know", vs. $15.7 \%$ among the physicians.

As regards a patient with a non-terminal illness again the physicians were more prepared to take action. However, the differences between physicians and nurses were not statistically significant.

\section{Differences among physicians with a special qualification in palliative care and pain medicine}

Physicians with a special qualification in palliative care were more reluctant to hasten a patient's death through euthanasia or PAS both in terminal and non-terminal 
Table 3 Responses of physicians and nurses questions 1 to 4

\begin{tabular}{|c|c|c|c|c|}
\hline Question & Answer & Physicians n (\%) & Nurses $n(\%)$ & Total $n(\%)$ \\
\hline \multirow{3}{*}{$\begin{array}{l}\text { 1. A patient has an incurable, painful illness, from which they will die, for example } \\
\text { cancer. Would you fulfill his wish and end his life using medication? }\end{array}$} & Yes & $14(7.1)^{*}$ & $11(4.0)$ & $25(5.3)$ \\
\hline & No & $164(82.8)^{*}$ & $210(77.2)$ & $374(79.6)$ \\
\hline & I don't know & $20(10.1)^{*}$ & $49(18.0)$ & $69(14.7)$ \\
\hline \multirow{3}{*}{$\begin{array}{l}\text { 2. If this patient asks for it, would you give him lethal medication so that he can } \\
\text { end his own life? }\end{array}$} & Yes & $31(15.7)^{*}$ & $30(11.0)$ & $61(13)$ \\
\hline & No & $136(68.7)^{*}$ & $174(64.0)$ & $310(66)$ \\
\hline & I don't know & $31(15.7)^{*}$ & 65 (23.9) & $96(20.4)$ \\
\hline \multirow{3}{*}{$\begin{array}{l}\text { 3. A patient has an incurable, painful illness, from which they will not die. Would } \\
\text { you fulfill his wish and end his life using medication? }\end{array}$} & Yes & $4(2.0)$ & $1(0.4)$ & $5(1.1)$ \\
\hline & No & $181(91.4)$ & $244(89.7)$ & $425(90.4)$ \\
\hline & I don't know & $23(8.5)$ & $23(8.5)$ & $36(7.7)$ \\
\hline \multirow{3}{*}{$\begin{array}{l}\text { 4. If this patient asks for it, would you give him lethal medication so that he can } \\
\text { end his own life? }\end{array}$} & Yes & $8(4.0)$ & $6(2.2)$ & $14(3)$ \\
\hline & No & 177 (89.4) & $242(89.0)$ & $419(89.1)$ \\
\hline & I don't know & $13(6.6)$ & $22(8.1)$ & $35(7.4)$ \\
\hline
\end{tabular}

${ }^{*} p \leq 0.05$

illness (Table 4). Only $3.7 \%$ of the physicians with special qualification in palliative care were willing to perform euthanasia in case of a terminal illness vs. $11.2 \%$ of the physicians without this special qualification $(\mathrm{p} \leq 0.001)$. For PAS in terminal illness, it was $11.9 \%$ vs. $20.2 \%$.

Physicians with a special qualification in pain medicine on the other hand were more prone to euthanasia or PAS in case of a terminal illness than physicians without this special qualification: $8.3 \%$ were willing to perform euthanasia vs. $6.5 \%$ among physicians without this qualification. In case of a non-terminal illness it was the other way around: physicians with special qualification in pain medicine were more reluctant to hasten a patient's death through euthanasia or PAS.
Thirty-three physicians had the special qualification in both palliative care and pain medicine. Overall the differences between this group and the physicians that did not have both special qualifications were not statistically significant.

Physicians without any special qualification in either palliative care or pain medicine were more willing to perform euthanasia in both terminal and non-terminal illness. However, the differences were not statistically significant.

\section{Decision-making}

The majority of the respondents would not make the decision about euthanasia or PAS by themselves (64.5\%) but would consult with a colleague first, $59.6 \%$. This was true both for physicians and nurses (Table 5).

Table 4 Responses of physicians with or without special qualification in palliative care or pain medicine

\begin{tabular}{|c|c|c|c|c|c|c|}
\hline Question & Answer & $\begin{array}{l}\text { Special } \\
\text { qualification in } \\
\text { palliative care } \\
n(\%)\end{array}$ & $\begin{array}{l}\text { No special } \\
\text { qualification in } \\
\text { palliative care } \\
n(\%)\end{array}$ & $\begin{array}{l}\text { Special } \\
\text { qualification in } \\
\text { pain medicine } \\
n(\%)\end{array}$ & $\begin{array}{l}\text { No special } \\
\text { qualification in } \\
\text { pain medicine } \\
n(\%)\end{array}$ & $\begin{array}{l}\text { No special qualification } \\
\text { in either palliative care } \\
\text { or pain medicine } \\
n(\%)\end{array}$ \\
\hline \multirow{3}{*}{$\begin{array}{l}\text { 1. A patient has an incurable, painful } \\
\text { illness, from which they will die, for } \\
\text { example cancer. Would you fulfill his } \\
\text { wish and end his life using medication? }\end{array}$} & Yes & $4(3.7)^{* *}$ & $10(11.2)^{* *}$ & $5(8.3)$ & $9(6.5)$ & $6(12.8)$ \\
\hline & No & $99(90.8)^{* *}$ & $65(73.0)^{* *}$ & $49(81.7)$ & 115 (83.3) & $35(74.5)$ \\
\hline & I don't know & $6(5.5)^{* *}$ & $14(15.7)^{* *}$ & $6(10.0)$ & $14(10.1)$ & $6(12.8)$ \\
\hline \multirow{3}{*}{$\begin{array}{l}\text { 2. If this patient asks for it, would you } \\
\text { give him lethal medication so that he } \\
\text { can end his own life? }\end{array}$} & Yes & $13(11.9)$ & $18(20.2)$ & $14(23.3)$ & 17 (12.3) & $9(19.1)$ \\
\hline & No & $76(69.7)$ & $60(67.4)$ & $39(65.0)$ & $97(70.3)$ & $32(68.1)$ \\
\hline & I don't know & $20(18.3)$ & $11(12.4)$ & $7(11.7)$ & $24(17.4)$ & $6(12.8)$ \\
\hline \multirow{3}{*}{$\begin{array}{l}\text { 3. A patient has an incurable, painful } \\
\text { illness, from which they will not die. } \\
\text { Would you fulfill his wish and end his } \\
\text { life using medication? }\end{array}$} & Yes & $2(1.8)$ & $2(2.2)$ & $1(1.7)$ & $3(2.2)$ & $2(4.3)$ \\
\hline & No & $103(94.5)$ & 78 (87.6) & $56(93.3)$ & 125 (90.6) & $39(83.0)$ \\
\hline & I don't know & $4(3.7)$ & $9(10.1)$ & $3(5.0)$ & $10(7.2)$ & $6(12.8)$ \\
\hline \multirow{3}{*}{$\begin{array}{l}\text { 4. If this patient asks for it, would you } \\
\text { give him lethal medication so that he } \\
\text { can end his own life? }\end{array}$} & Yes & $4(3.7)$ & $4(4.5)$ & $2(3.3)$ & $6(4.3)$ & $3(6.4)$ \\
\hline & No & 99 (90.8) & 78 (87.6) & $54(90.0)$ & $123(89.1)$ & $40(85.1)$ \\
\hline & I don't know & $6(5.5)$ & $7(7.9)$ & $4(6.7)$ & $9(6.5)$ & $4(8.5)$ \\
\hline
\end{tabular}

${ }^{* *} p \leq 0.001$ (regarding physicians with and without special qualification in palliative care) 
Table 5 Responses of physicians and nurses questions 5 to 8

\begin{tabular}{|c|c|c|c|c|}
\hline Question & Answer & Physicians $n(\%)$ & Nurses $n(\%)$ & Total $n(\%)$ \\
\hline \multirow[t]{4}{*}{ 5. I would make this decision by myself in order to not burden others } & Yes & $46(23.2)$ & $66(24.3)$ & $112(23.8)$ \\
\hline & No & $133(67.2)$ & $170(62.5)$ & $303(64.5)$ \\
\hline & I don't know & $35(7.4)$ & $12(6.1)$ & $35(7.4)$ \\
\hline & Not specified & $7(3.5)$ & $13(4.8)$ & $20(4.3)$ \\
\hline \multirow[t]{4}{*}{ 6. I would not make a decision without consulting my colleagues } & Yes & $123(62.1)$ & $157(57.7)$ & $280(59.6)$ \\
\hline & No & $51(25.8)$ & $60(22.1)$ & $111(23.6)$ \\
\hline & I don't know & $31(11.4)$ & $15(7.6)$ & $46(9,8)$ \\
\hline & Not specified & $9(4.5)$ & $24(8.8)$ & $33(7.0)$ \\
\hline \multirow[t]{4}{*}{ 7. I would first attempt to treat the patient's symptoms on order to change his wish } & Yes & $147(74.2)^{* *}$ & $151(55.5)$ & $298(63.4)$ \\
\hline & No & $24(12.1)^{* *}$ & $39(14.3)$ & $63(13.4)$ \\
\hline & I don't know & $21(10.6)^{* *}$ & $59(21.7)$ & $80(17.0)$ \\
\hline & Not specified & $6(3.0)^{* *}$ & $23(8.5)$ & $29(6.2)$ \\
\hline \multirow[t]{4}{*}{ 8. For this treatment attempt I would estimate for the following amount of time } & 1 week & $17(11.5)^{* *}$ & $35(23.0)$ & $52(11)$. \\
\hline & 2 weeks & $33(22.3)^{* *}$ & $50(32.9)$ & $83(17.7)$ \\
\hline & 4 weeks & $87(43.9)^{* *}$ & 47 (30.9) & $134(28.5)$ \\
\hline & Not specified & $11(7.4)^{* *}$ & $20(13.2)$ & $31(6.6)$ \\
\hline
\end{tabular}

${ }^{* *} p \leq 0.001$

Asked whether they would attempt to treat the symptoms before ending the patient's life the majority answered "yes": $63.4 \%$. The differences between physicians and nurses on this matter were significant: $74.2 \%$ of the physicians chose to treat the patient, while it was $55.5 \%$ of the nurses ( $\mathrm{p} \leq 0.001) .21 .7 \%$ of the nurses were undecided and chose "I don't know".

$58.8 \%$ of the physicians that would first attempt to treat the symptoms would estimate 4 weeks for the attempt to discover the conclusive patient's wish. Among the nurses it was $30.9 \%$ who would chose 4 weeks for the treatment attempt.

\section{Limitations}

Given that the study focused on attendants of a palliative care and pain conference the reference group holds a certain bias. However, it was the aim of the survey to explore the attitudes of professionals engaged in the field of palliative care and pain management specifically. Because of this bias the results obtained do not reflect the general opinion of German physicians and nurses but provide an insight on the point of view of those professionals faced with end-of-life decisions in daily practice. No control group was surveyed, because we were only interested in the possible focus group.

Some of the practices the questionnaire asked about are currently illegal in Germany. This might prevent the respondents from giving honest answers. To reduce the reluctance to answer honestly the questionnaire was anonymous [36].
Additionally the questionnaire at hand avoids terminology that provides a certain bias itself (e.g. the term "euthanasia"). The patient scenarios used are adapted from a questionnaire by Seale and were translated to German [7]. Accordingly, our case vignettes referred to a painful terminal or non-terminal illness to focus on a physical symptom. Pain has proven to be a valid and quantifiable indicator for unbearable suffering in patients at the end of their life [37]. The patient scenarios used are limited: patients with other illnesses than cancer such as dementia (which has become more and more relevant in our aging society) were not included. Those scenarios are a complex field that should be investigated separately.

Regarding the statistical analysis a post hoc performed logistic regression model concerning age, occupation and special qualification proved no significant results. This was not unexpected regarding the sample and its structure. Nevertheless this might point to possible deficits in the strength of the statistical significance of the data at hand.

\section{Discussion}

This is the first German study to ask about the willingness of professionals to take action as regards euthanasia and PAS without biased phrasing such as euthanasia from the Greek "help to die" in German "Sterbehilfe". Only few studies focused on palliative care professionals in particular [38-40]. This adds to the current debate: numerous studies regarding the general acceptance of euthanasia and PAS have been conducted [7, 38, 41, 42]. 
A recent study among German physicians showed that already now without legalization of PAS or euthanasia both practices are performed by a minority [43]. This holds also true for members of the German Society for Palliative Care [38]. These findings are based on the EURELD-questionnaire, which focused on physicians' and their colleagues' experiences with patients that died within the last 12 months [33]. However, this questionnaire combines questions regarding euthanasia or PAS - which are currently illegal - with questions regarding established end of life care measures such as "withdrawing", "withholding", or "intensifying" treatment thus making answers dubious. Several studies have demonstrated that physicians have difficulties in discriminating between euthanasia and palliative sedation or euthanasia and intensified pain relief and lack knowledge regarding the procedure $[19,44-46]$. Unlike the Eureld-questionnaire we used concrete patient vignettes to explore the willingness to act thus allowing a clear insight into the physicians' willingness to actively end their patient's life.

\section{General acceptance and willingness to act}

The general support regarding the legalization of euthanasia and PAS is respectively high in Germany [12]. However, the willingness to perform these practices is low: only $5.3 \%$ of the respondents would be willing to perform euthanasia on a patient with a terminal illness. This is in line with previous studies among professionals and medical students thus emphasizing that general acceptance and willingness to perform differ widely and have to be looked at independently $[8,11,15,29]$. Similar results were reported from Finland: over time the attitude towards euthanasia became more positive, however, this change did not apply to the willingness to act [11]. This is also true in countries that have legalized euthanasia or PAS, such as Belgium: Even there the willingness to perform these practices is limited among general practitioners [13].

\section{Physicians vs. nurses}

The differences in the attitudes of physicians and nurses are remarkable: Physicians are more willing to take action than nurses both in case of a terminal and a nonterminal illness. This result is surprising since former studies prompted to nurses being supportive of euthanasia and PAS [26, 29, 41, 42, 47]. However, a study among critical care nurses from Israel also found nurses to be supportive of PAS but only few agreed to participate in this act [48].

One reason for the nurses' reluctance to take action might be that the nurses' role in the performance of these end of life practices is still unclear even in countries that have legalized these practices [29]. However, in
Germany a number of cases have been reported of nurses going beyond the professional and legal boundaries and administering drugs to end the patient's life without the patient's $[49,50]$. These cases show the necessity to also investigate nurses regarding end of life questions.

In Belgium law requires the physicians to discuss the euthanasia request with the nursing team in charge (Chapter II section $3, \mathbb{\$} 2.4$ ), which shows that nurses do play an important role in end of life practices. This is particularly true since it is often the nurses that patients talk to about their wishes [29]. The role of nurses in end of life decision-making is also mirrored in other studies. Nurses are involved both in the decision making process and the administration of the death hastening drugs [27].

In some cases euthanasia and PAS were even performed without request of the patient [27]. This does not seem to be a singular phenomenon: a Canadian study showed that about $63 \%$ of the nurses asked would be willing to perform euthanasia without knowing the patient's wish [16]. Among the physicians it was only one third that were willing to perform euthanasia without knowing the patient's wish concerning an act of euthanasia [17]. A Belgian study based on a death certificate survey in 2007 identified 66 cases of euthanasia "without explicit request" by the patient [51, 52]. To further investigate what "without explicit request" meant another study was performed and those cases were analyzed once more [52]: The findings showed that most of these cases could not be described as "non-voluntary ending of life" thus the label "without explicit request" is misleading.

A study among 1509 Dutch nurses showed that the majority of hospital nurses did not accept inserting an infusion needle to administer a fatal dose as a task for nurses, serving on a review-board for euthanasia cases was accepted only by $45 \%$ of the nurses asked [9]. A study from Spain found $51.5 \%$ of the nurses willing to perform euthanasia if legalized [14]. However, about one third of those nurses could not identify a case of PAS correctly or report the legal status of PAS in Spain [14].

\section{Special qualification}

In line with previous studies we found physicians with a special qualification in palliative care to be more reluctant to end their patient's life [7, 53-55]. However, physicians with a special qualification only in pain medicine were more open to performing these acts.

Little is known about factors influencing a physician's willingness to perform EOL practices. A Canadian study among physicians of various specialties showed that "perceived behavioral control" was one of the main determinants for the willingness to perform euthanasia 
[17]. Moreover former experience in the field of euthanasia and PAS has also proven to determine future willingness to take part in these practices [56].

\section{Differences in the willingness to perform euthanasia or PAS}

Our results show more willingness to perform PAS than euthanasia among the professionals, thus leaving the final responsibility to the patient himself. $13 \%$ of the respondents willing to perform PAS on a patient with a terminal disease is a remarkable amount. This is in line with the emphasis put on the patient autonomy [57]. However, previous studies in Spain and Northern Ireland found more willingness to be involved in euthanasia rather than PAS $[14,15]$. This hints to a more paternalistic approach with euthanasia leaving it to the physician to take action and end the patients' life rather than the patient ending his own life by taking the lethal medication.

These diverse interpretations of the performance of euthanasia and PAS can also be found in the Netherlands, where both practices are legal: PAS is perceived to leave more responsibility to the patient himself, safeguarding his autonomy while at the same time leaving less burden to the physician [57].

\section{Decision making process}

One aspect that has not been in the focus of research yet is the final decision making process. Our results show that the majority of the health care professionals asked would interact with a colleague before granting a request to hasten the patient's death: $59.6 \%$ of the respondents would consult a colleague first before coming to a decision. The need for a second opinion is also demanded in countries that have legalized euthanasia or PAS, e. g. Belgium or the Netherlands, where the consultation of a second physicians or a euthanasia review committee is a procedural requirement [58].

Facing these legal regulations and European guidelines on palliative sedation, merely $60 \%$ consulting others before life-ending decisions is a low figure [59]. However, this figure is in line with data from the Netherlands and Belgium indicating that the need for consultation is not accepted by all physicians [60-62]. In about $35 \%$ of the cases of ending of life without explicit request by the patient no consultation took place in advance [6].

\section{Treatment attempt}

Requests for euthanasia or PAS also occur in palliative care settings [63, 64]. Some argue that there is a "synergistic relationship" between palliative care and euthanasia or PAS, which means both of those practices could be embraced in the palliative care setting as possible therapeutic measures [22, 64]. The EAPC task force, however, argues clearly that euthanasia or PAS should not fall into the responsibility of palliative care [2]. The vital role of palliative care in the debate is also mirrored in our results with $63.4 \%$ of the respondents wanting to attempt to treat the patient's symptoms first before making any ultimate decisions. Some have even argued that in the absence of palliative care patients would not be able to make an informed meaningful decision $[65,66]$. This however, has been disputed in the literature arguing that an autonomous decision regarding euthanasia or PAS is not limited to patients that are being treated in an ideal setting i.e. one that provides palliative care [67]. Nevertheless even liberal authors emphasize the importance of enhancing palliative care and its availability in the light of legalizing euthanasia or PAS [68].

A caveat is represented by studies demonstrating that the patients' wish to die often changes over time and euthanasia requests are withdrawn $[23,63,69]$. A treatment attempt could buy some time to secure that the patient's wish to die is not just temporary. Furthermore this also leaves room to provide the patients with more information regarding end of life, euthanasia or palliative sedation, which has proven to be important in their decision-making [70].

Regarding the length of the treatment attempt the majority of physicians estimated 4 weeks to be needed. Keeping in mind that depression can be a problem in patients at the end of their life [71] and that antidepressants take about 2 to 3 weeks to take effect this finding is not surprising.

\section{Conclusions}

Our results demonstrate a profound problem in the actual discussion about PAS in Germany: if PAS were allowed, who should perform it. General practitioners are not trained to perform any form of life-ending procedures. This has been documented extensively by studies from Belgium and the Netherlands, where false drugs were selected, euthanasia was mistaken for palliative sedation and vice versa $[44,61,72-75]$. On the other hand, palliative care physicians are reluctant to perform euthanasia or PAS. So far public debate has disregarded the central question: who should train doctors to perform PAS correctly.

Thereby our study should stimulate an ongoing discussion before opening political discussions to allow or prohibit PAS for physicians in Germany.

\section{Abbreviations}

PAS: Physician assisted suicide; EOL: End of life.

\section{Competing interests}

The authors declare no conflict of interest.

\section{Authors' contributions}

JZ was responsible for data collection, statistical analysis, literature research and writing the initial and final draft of the manuscript. MT revised the 
manuscript. MZ was responsible for the study design, supported the literature research and revised the manuscript. All authors read and approved the final manuscript.

\section{Funding}

We acknowledge support by the German Research Foundation and the Open Access Publication Funds of the Ruhr-Universität Bochum.

\section{Author details}

${ }^{1}$ Ruhr-University Bochum, Universitätstr. 150, D 44801 Bochum, Germany.

${ }^{2}$ Clinic for Anaesthesiology, Intensive Care and Pain Medicine,

Moenchebergstraße 41-43, D 34125 Kassel, Germany.

\section{Received: 12 August 2015 Accepted: 6 November 2015} Published online: 14 November 2015

\section{References}

1. Holm S. The debate about physician assistance in dying: 40 years of unrivalled progress in medical ethics? J Med Ethics. 2015;41:40-3.

2. Materstvedt LJ, Clark D, Ellershaw J, Førde R, Gravgaard AM, Müller-Busch HC, et al. Euthanasia and physician-assisted suicide: a view from an EAPC Ethics Task Force. Palliat Med. 2003;17:97-101. discussion 102-179.

3. Nauck F, Ostgathe C, Radbruch L. Ärztlich assistierter Suizid: Hilfe beim Sterben - keine Hilfe zum Sterben. Dtsch Arztebl. 2014;111:A 67-71.

4. Melching $\mathrm{H}$. Thoughts on the current euthanasia debate from the perspective of the German Society for Palliative Care. Schmerz. 2015;29:261-5.

5. Allensbacher-Archiv. IfD-Umfragen 10023, 11029. 2014.

6. van der Heide A, Onwuteaka-Philipsen BD, Rurup ML, Buiting HM, van Delden JJ, Hanssen-de Wolf JE, et al. End-of-life practices in the Netherlands under the Euthanasia Act. N Engl J Med. 2007;356:1957-65.

7. Seale C. Legalisation of euthanasia or physician-assisted suicide: survey of doctors' attitudes. Palliat Med. 2009;23:205-12.

8. Leppert W, Majkowicz M, Forycka M. Attitudes of Polish physicians and medical students toward breaking bad news, euthanasia and morphine administration in cancer patients. J Cancer Educ. 2013;28:603-10.

9. van Bruchem-van de Scheur A, van der Arend A, van Wijem F, Abu-Saad $\mathrm{HH}$, ter Meulen R. Dutch Nurses' attitudes towards euthanasia and physician assisted suicide. Nurs Ethics. 2008;15(2):186-98.

10. Kouwenhoven PS, Raijmakers NJ, van Delden JJ, Rietjens JA, van Tol DG, van de Vathorst S, et al. Opinions of health care professionals and the public after eight years of euthanasia legislation in the Netherlands: a mixed methods approach. Palliat Med. 2013;27:273-80.

11. Louhiala P, Enkovaara $H$, Halila H,Pälve H, Vänskä J . Finnish physicians' attitudes towards active euthanasia have become more positive over the last 10 years. J Med Ethics. 2015;41:353-5.

12. Sozialwissenschaftliches Institut der EKD https://www.ekd.de/download/ 150512_Ergebnisse_Umfrage_zum_Sterben.pdf.

13. Sercu M, Pype P, Christiaens T, Grypdonck M, Derese A, Deveugele M. Are general practitioners prepared to end life on request in a country where euthanasia is legalised? J Med Ethics. 2012;38:274-80.

14. Tamayo-Velázquez MI, Simón-Lorda P, Cruz-Piqueras M. Euthanasia and physician-assisted suicide: knowledge, attitudes and experiences of nurses in Andalusia (Spain). Nurs Ethics. 2012;19:677-91.

15. McGlade KJ, Slaney L, Bunting BP,Gallagher AG. Voluntary euthanasia in Northern Ireland: general practitioners' beliefs, experiences, and actions. $\mathrm{Br} J$ Gen Pract. 2000;50:794-7.

16. Lavoie M, Godin G, Vézina-Im LA, Blondeau D, Martineau I, Roy L. Psychosocial determinants of nurses' intention to practise euthanasia in palliative care. Nurs Ethics. 2014. [Epub ahead of print].

17. Lavoie M, Godin G, Vézina-Im LA, Blondeau D, Martineau I, Roy L. Psychosocial determinants of physicians' intention to practice euthanasia in palliative care. BMC Med Ethics. 2015;16:6.

18. Hasselaar JG, Reuzel RP, van den Muijsenbergh ME, Koopmans RT, Leget CJ, Crul BJ, et al. Dealing with delicate issues in continuous deep sedation. Varying practices among Dutch medical specialists, general practitioners, and nursing home physicians. Arch Intern Med. 2008;168:537-43.

19. Anquinet L, Rietjens JA, Mathers N, Seymour J, van der Heide A, Deliens L, et al. Descriptions by general practitioners and nurses of their collaboration in continuous sedation until death at home: in-depth qualitative interviews in three European countries. J Pain Symptom Manage. 2015;49:98-109.

20. Social-Code S. http://www.gesetze-im-internet.de/sgb_5/_37b.html.
21. Schneider W, Eichner E, Thoms U, Stadelbacher S, Kopitzsch F. Specialised out-patient palliative care (SAPV) in Bavaria: efficiency, structural and process-related effects and rural care. Gesundheitswesen. 2015;77:219-24.

22. Bernheim JL, Distelmans W, Mullie A, Ashby MA. Questions and answers on the Belgian model of integral end-of-life care: experiment? Prototype? : "Eu-euthanasia": the close historical, and evidently synergistic, relationship between palliative care and euthanasia in Belgium: an interview with a doctor involved in the early development of both and two of his successors. J Bioeth Inq. 2014;11:507-29.

23. Van Wesemael Y, Cohen J, Bilsen J, Smets T, Onwuteaka-Philipsen B, Deliens $L$. Process and outcomes of euthanasia requests under the belgian act on euthanasia: a nationwide survey. J Pain Symptom Manage. 2011;42:721-33.

24. Bernheim JL, Deschepper R, Distelmans W, Mullie A, Bilsen J, Deliens L. Development of palliative care and legalisation of euthanasia: antagonism or synergy? BMJ. 2008;336:864-7.

25. Zenz J, Tryba M, Zenz M. Physician-assisted dying: acceptance by physicians only for patients close to death. Pain Ther. 2014;3:103-12

26. Zenz J, Tryba M, Zenz M. Euthanasia and physician-assisted suicide: attitudes of physicians and nurses. Schmerz. 2015;29:211-6.

27. Inghelbrecht E, Bilsen J, Mortier F,Deliens L. The role of nurses in physicianassisted deaths in Belgium. CMAJ. 2010;182:905-10.

28. deVeer A, Francke A, Poortvliet E. Nurses' involvement in end-of-life decisions. Cancer Nurse. 2008;31(3):222-8.

29. Inghelbrecht E, Bilsen J, Mortier F,Deliens L. Attitudes of nurses towards euthanasia and towards their role in euthanasia: a nationwide study in Flanders, Belgium. Int J Nurs Stud. 2009;46:1209-18.

30. Bilsen JJ, Vander Stichele RH, Mortier F,Deliens L. Involvement of nurses in physician-assisted dying. J Adv Nurs. 2004;47:583-91.

31. Giese C. German nurses, euthanasia and terminal care: a personal perspective. Nurs Ethics. 2009;16:231-7.

32. Berghs M, Dierckx de Casterlé B, Gastmans C. The complexity of nurses' attitudes toward euthanasia: a review of the literature. J Med Ethics. 2005;31:441-6.

33. van der Heide A, Deliens L, Faisst K, Nilstun T, Norup M, Paci E, et al. End-oflife decision-making in six European countries: descriptive study. Lancet. 2003:362:345-50.

34. Clery E, McLean S, Phillips M. Quickening Death: The euthanasia debate. In: Park A, Curtice J, Thomson K, et al., editors. Hrsg. British social attitudes: perspectives on changing a society 23 rd annual report. London: Sage; 2007. p. 35-54.

35. Emanuel EJ. Euthanasia and physician-assisted suicide: a review of the empirical data from the United States. Arch Intern Med. 2002;162:142-52.

36. Merry AF, Moharib M, Devcich DA, Webster ML, Ives J, Draper H. Doctors' willingness to give honest answers about end-of-life practices: a crosssectional study. BMJ Open. 2013;3(5). doi:10.1136/bmjopen-2013-002598

37. Ruijs CD, van der Wal G, Kerkhof AJ, Onwuteaka-Philipsen BD. Unbearable suffering and requests for euthanasia prospectively studied in end-of-life cancer patients in primary care. BMC Palliat Care. 2014;13:62

38. Schildmann J, Hoetzel J, Mueller-Busch C,Vollmann J. End-of-life practices in palliative care: a cross sectional survey of physician members of the German Society for Palliative Medicine. Palliat Med. 2010;24:820-7.

39. Müller-Busch HC, Oduncu FS, Woskanjan S, Klaschik E. Attitudes on euthanasia, physician-assisted suicide and terminal sedation-a survey of the members of the German Association for Palliative Medicine. Med Health Care Philos. 2004;7:333-9.

40. Schildmann J, Hoetzel J, Baumann A, Müller-Busch C, Vollmann J. Limitation of treatment at the end of life: an empirical-ethical analysis regarding the practices of physician members of the German Society for Palliative Medicine. J Med Ethics. 2011;37:327-32.

41. Glebocka A, Gawor A, Ostrowski F. Attitudes toward euthanasia among Polish physicians, nurses and people who have no professional experience with the terminally ill. Adv Exp Med Biol. 2013;788:407-12.

42. Bendiane MK, Galinier A, Favre R, Ribiere C, Lapiana JM, Obadia Y et al. French district nurses' opinions towards euthanasia, involvement in end-oflife care and nurse patient relationship: a national phone survey. J Med Ethics. 2007;33:708-11.

43. Schildmann J, Dahmen B, Vollmann J. End-of-life practices of physicians in Germany. Dtsch Med Wochenschr. 2015;140:e1-6.

44. Rietjens J, van Delden J, Onwuteaka-Philipsen B, Buiting H, van der Maas P, van der Heide A. Continuous deep sedation for patients nearing death in the Netherlands: descriptive study. BMJ. 2008;336:810-3. 
45. Klosa PR, Klein C, Heckel M, Bronnhuber AC, Ostgathe C, Stiel S. The EAPC framework on palliative sedation and clinical practice-a questionnaire-based survey in Germany. Support Care Cancer. 2014;22:2621-8.

46. Rietjens JA, van der Heide A, Vrakking AM,Onwuteaka-Philipsen BD, van der Maas PJ, van der Wal G. Physician reports of terminal sedation without hydration or nutrition for patients nearing death in the Netherlands. Ann Intern Med. 2004;141:178-85.

47. Musgrave CF, Margalith I, Goldsmidt L. Israeli oncology and nononcology nurses' attitudes toward physician-assisted dying: a comparison study. Oncol Nurs Forum. 2001;28:50-7.

48. Dekeyser Ganz F, Musgrave CF. Israeli critical care nurses' attitudes toward physician-assisted dying. Heart Lung. 2006;35:412-22.

49. BBC. http://news.bbc.co.uk/2/hi/europe/4689006.stm. In. BBC

50. Spiegel. http://www.spiegel.de/international/germany/german-nurse-ontrial-angel-of-death-says-she-killed-patients-to-help-them-a-478088.html. In. Spiegel Online international.

51. Chambaere K, Bilsen J, Cohen J, Pousset G, Onwuteaka-Philipsen BD, Mortier $F$, et al. A post-mortem survey on end-of-life decisions using a representative sample of death certificates in Flanders, Belgium: research protocol. BMC Public Health. 2008;8:299.

52. Chambaere K, Bernheim JL, Downar J, Deliens L. Characteristics of Belgian "life-ending acts without explicit patient request": a large-scale death certificate survey revisited. CMAJ Open. 2014;2:E262-7.

53. Lee W, Price A, Rayner L, Hotopf M. Survey of doctors' opinions of the legalization of physician assisted suicide. BMC Med Ethics. 2009;10:2.

54. Marini MC, Neuenschwander H, Stiefel F. Attitudes toward euthanasia and physician assisted suicide: a survey among medical students, oncology clinicians, and palliative care specialists. Palliat Support Care. 2006:4:251-5.

55. Parker MH, Cartwright CM, Williams GM. Impact of specialty on attitudes of Australian medical practitioners to end-of-life decisions. Med J Aust. 2008; 188:450-6.

56. Vézina-Im LA, Lavoie M, Krol P, Olivier-D'Avignon M. Motivations of physicians and nurses to practice voluntary euthanasia: a systematic review. BMC Palliat Care. 2014;13:20.

57. Kouwenhoven PS, van Thiel GJ, Raijmakers NJ, Rietjens JA, van der Heide A van Delden JJ. Euthanasia or physician-assisted suicide? A survey from the Netherlands. Eur J Gen Pract. 2014;20:25-31.

58. Adams $\mathrm{M}$, Nys $\mathrm{H}$. Comparative reflections on the Belgian Euthanasia Act 2002. Med Law Rev. 2003;11:353-76.

59. Cherny NI, Radbruch L, Care BotEAfP. European Association for Palliative Care (EAPC) recommended framework for the use of sedation in palliative care. Palliat Med. 2009;23:581-93.

60. Pereira J. Legalizing euthanasia or assisted suicide: the illusion of safeguards and controls. Curr Oncol. 2011;18:e38-45.

61. Chambaere K, Bilsen J, Cohen J, Onwuteaka-Philipsen BD, Mortier F, Deliens L. Physician-assisted deaths under the euthanasia law in Belgium: a population-based survey. CMAJ. 2010;182:895-901.

62. Smets T, Bilsen J, Cohen J, Rurup ML, Mortier F, Deliens L. Reporting of euthanasia in medical practice in Flanders, Belgium: cross sectional analysis of reported and unreported cases. BMJ. 2010;341:c5174.

63. Guirimand F, Dubois E, Laporte L, Richard JF, Leboul D. Death wishes and explicit requests for euthanasia in a palliative care hospital: an analysis of patients files. BMC Palliat Care. 2014;13:53.

64. Van den Block L, Deschepper R, Bilsen J, Bossuyt N, van Casteren V, Deliens L. Euthanasia and other end of life decisions and care provided in final three months of life: nationwide retrospective study in Belgium. BMJ. 2009; 339:b2772.

65. Shariff MJ. Navigating assisted death and end-of-life care. CMAJ. 2011;183:643-4.

66. Shariff MJ. The dying need proper care before we settle assisted suicide. Lawyers Weekly. 2010;30:5-6.

67. Barutta J, Vollmann J. Physician-assisted death with limited access to palliative care. J Med Ethics. 2015;41:652-4.

68. Hudson P, Hudson R, Philip J, Boughey M, Kelly B, Hertogh C. Legalizing physician-assisted suicide and/or euthanasia: Pragmatic implications. Palliat Support Care. 2015 Oct;13(5):1399-409.
69. Johansen S, Hølen JC, Kaasa S,Loge HJ, Materstvedt LJ. Attitudes towards, and wishes for, euthanasia in advanced cancer patients at a palliative medicine unit. Palliat Med. 2005;19:454-60.

70. Pestinger M, Stiel S, Elsner F, Widdershoven G, Voltz R, Nauck F et al. The desire to hasten death: using Grounded Theory for a better understanding "When perception of time tends to be a slippery slope". Palliat Med. 2015; 29:711-9.

71. van der Lee ML, van der Bom JG, Swarte NB, Heintz AP, de Graeff A, van den Bout J. Euthanasia and depression: a prospective cohort study among terminally ill cancer patients. J Clin Oncol. 2005;23:6607-12.

72. Deyaert J, Chambaere K, Cohen J, Roelands M, Deliens L. Labelling of endof-life decisions by physicians. J Med Ethics. 2014;40:505-7.

73. Onwuteaka-Philipsen BD, Brinkman-Stoppelenburg A, Penning C, de JongKrul GJ, van Delden JJ, van der Heide A. Trends in end-of-life practices before and after the enactment of the euthanasia law in the Netherlands from 1990 to 2010: a repeated cross-sectional survey. Lancet. 2012;380:90815.

74. Buiting HM, van der Heide A, Onwuteaka-Philipsen BD, Rurup ML, Rietjens JA, Borsboom G, et al. Physicians' labelling of end-of-life practices: a hypothetical case study. J Med Ethics. 2010;36:24-9.

75. Chambaere K, Bilsen J, Cohen J, Rietjens JA, Onwuteaka-Philipsen BD, Mortier $\mathrm{F}$, et al. Continuous deep sedation until death in Belgium: a nationwide survey. Arch Intern Med. 2010;170:490-3.

\section{Submit your next manuscript to BioMed Central and take full advantage of:}

- Convenient online submission

- Thorough peer review

- No space constraints or color figure charges

- Immediate publication on acceptance

- Inclusion in PubMed, CAS, Scopus and Google Scholar

- Research which is freely available for redistribution 